\title{
Meningkatkan Respon Belajar Siswa Melalui Pembelajaran Multimedia Terintegrasi Kurikulum dengan Sistem shift
}

\author{
Kadek Wikan Paramasila ${ }^{*}$ \\ ${ }^{1}$ Manajemen Informatika, Politeknik Ganesha Guru, Denpasar, Indonesia
}

\section{A R T I CLE I N F O}

Article history:

Received October 01, 2021

Revised October 02, 2021

Accepted November 25, 2021

Available online December 25, 2021

Kata Kunci:

Multimedia Interaktif, Integrated Curicculum

Keywords:

Interactive Multimedia, Integrated Curiculum

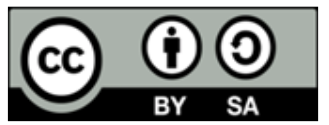

This is an open access article under the CC BY-SA license.

Copyright () 2021 by Author. Published by Universitas Pendidikan Ganesha.

\section{A B S T R A K}

Rendahnya respon belajar siswa disebabkan adanya pandemi covid-19. Pandemi Covid-19 telah memicu perubahan signifikan dalam sistem pendidikan di seluruh dunia yang mengakibatkan penutupan sekolah sehingga sistem pengajaran harus beralih dari pelajaran tatap muka menjadi model yang sepenuhnya virtual. Salah satu caranya adalah dengan membuat pembelajaran berbasis multimedia. Tujuan dari penelitian ini yaitu menciptakan produk ajar multimedia interaktif yang dapat meningkatkan respon belajar siswa, khususnya pada pembelajaran praktik animasi 2 dimensi. Metode penelitian yang digunakan adalah Research \& Development dengan menggunakan model Borg \& Gall. Subjek dalam penelitian ini adalah ahli desain, ahli media, ahli isi dan siswa kelas XI Multimedia. Metode pengumpulan data dilakukan dengan metode wawancara dan angket dengan menggunakan teknik analisis desktiptif kuantitatif. Hasil penelitian menunjukkan bahwa ahli media memperoleh kalkulasi $87 \%$, ahli desain memperoleh $89 \%$ dan ahli isi memperoleh $88 \%$. Selanjutnya ujicoba dilakukan oleh siswa kelas $\mathrm{XI}$ Multimedia dengan hasil yaitu uji perseorangan memperoleh hasil $90 \%$, ujicoba kelompok kecil memperoleh $91 \%$ dan ujicoba kelompok besar memperoleh $89 \%$. Dari analisis ujicoba yang sudah dilakukan membuktikan bahwa multimedia interaktif berbasis Integrated curriculum dengan Shift Mode pada pembelajaran praktik animasi 2 dimensi efektif dan layak digunakan. Implikasi penelitian yang telah dilakukan dengan memanfaatkan multimedia interaktif berbasis Integrated curriculum adalah terjadi peningkatan respon belajar siswa sehingga berdampak langsung terhadap semangat belajar siswa dan keaktifan serta partisipasi siswa dalam pembelajaran, karena dapat digunakan sebagai media pembelajaran mandiri.

\section{A B S T RA CT}

The low response to student learning is due to the COVID-19 pandemic. The Covid-19 pandemic has triggered significant changes in education systems around the world which have resulted in school closures requiring the teaching system to shift from face-to-face lessons to a completely virtual model. One way is to make multimedia-based learning. This study aims to create interactive multimedia teaching products that will be able to improve student learning responses, especially in learning 2dimensional animation practice. The research method used is Research \& Development using the Borg \& Gall model. The subjects in this study were design experts, media experts, content experts, and students of class XI Multimedia. Data collection using interviews and questionnaires using quantitative descriptive analysis techniques. The results showed that media experts got $87 \%$ calculations, design experts got $89 \%$ and content experts got $88 \%$. Furthermore, the test was carried out by students of class XI Multimedia with the results that the individual test obtained $90 \%$ results, the small group trial obtained $91 \%$ and the large group trial obtained $89 \%$. From the analysis of trials that have been carried out, it proves that interactive multimedia based on Integrated Curriculum with Shift Mode in 2-dimensional animation practice learning is effective and feasible to use. The implication of the research that has been carried out by utilizing interactive multimedia based on the Integrated Curriculum is that there is an increase in student learning responses so that it has a direct impact on students' enthusiasm for learning and student activity and participation in learning because it can be used as an independent learning medium. 


\section{PENDAHULUAN}

Perkembangan ilmu pengetahuan dan teknologi telah membawa perubahan yang sangat signifikan terhadap berbagai dimensi kehidupan manusia khususnya dalam bidang pendidikan dan banyaknya permasalahan dalam bidang pendidikan memerlukan inovasi dalam proses pembelajaran sehingga nantinya diharapkan mampu memecahkan masalah yang ada sehingga dapat meningkatkan mutu dan hasil pendidikan. (HM, 2018; Sujana, 2019). Proses pembelajaran menjadi sebuah upaya bersama antara guru dan siswa untuk berbagi dan mengolah informasi dengan tujuan agar pengetahuan yang terbentuk dalam diri siswa dan menjadi landasan belajar secara mandiri dan berkelanjutan. Kriteria keberhasilan sebuah proses pembelajaran adalah munculnya kemampuan belajar berkelanjutan secara mandiri (Diputra, 2016; Hanik, 2020). Sebuah proses pembelajaran yang baik, paling tidak harus melibatkan tiga aspek yaitu aspek psikomotorik, aspek kognitif dan aspek afektif (Kuswanto \& Walusfa, 2017; Persada et al., 2020). Tercapainya hasil belajar seseorang dapat dilihat dari respon yang diberikan oleh siswa dalam mengikuti proses pembelajaran yang dapat menantang siswa untuk terlibat penuh dalam proses pembelajaran. Suatu interaksi pembelajaran di dalamnya terdapat partisipasi siswa yang satu dengan yang lain berbeda-beda dalam keaktifannya."Hal ini disebabkan oleh proses pembelajaran siswa yang berbeda-beda pula. Ada sikap siswa yang terlibat aktif dalam suatu interaksi edukatif, juga ada siswa yang bersikap kurang aktif. Siswa yang aktif dalam proses pembelajaran"jika kemampuan gurunya baik dan sebaliknya. Dengan adanya proses pembelajaran siswa yang baik, maka akan tercipta keberhasilan siswa dalam belajar

Namun kenyataan saat ini, respon belajar siswa menurun. Hal ini disebabkan adanya pandemi covid-19. Pandemi Covid-19 telah memicu perubahan signifikan dalam sistem pendidikan di seluruh dunia yang mengakibatkan penutupan sekolah sehingga sistem pengajaran harus beralih dari pelajaran tatap muka menjadi model yang sepenuhnya virtual. (Quezada et al., 2020; Sepulveda-Escobar \& Morrison, 2020). Selama pandemi COVID-19, sekolah jarang melakukan interaksi tatap muka, sehingga pendidik menciptakan konteks pembelajaran dengan menggunakan jenis interaksi campuran di sekolah dan rumah untuk membantu siswa dalam proses pembelajaran, dan orang tua juga terlibat dan memberikan dukungan dalam proses pembelajaran tersebut (Apriyanti, 2020; Borup et al., 2020; Graham et al., 2019) Khususnya di SMK Negeri 1 Kintamani yang merupakan sekolah dengan pendidikan kejuruan memegang peranan yang sangat penting dalam mempersiapkan siswa agar mampu bersaing di dunia usaha dan dunia industri sesuai dengan bidang keahliannya dan penilaian kemampuan siswa harus mengacu pada standar dunia kerja (Firdausi \& Barnawi, 2012). Selain itu, praktik pembelajaran animasi 2 Dimensi tidak berjalan sepenuhnya. Berdasarkan hasil wawancara guru mata pelajaran animasi yang menyatakan bahwa pembelajaran praktek pada masa pandemi covid-19 tidak dapat berjalan karena keterbatasan sarana dan prasarana seperti sinyal internet di daerah pegunungan sangat lemah, dan terbatas hanya mampu menjangkau beberapa siswa, masalah biaya yang harus dikeluarkan untuk pembelajaran online (Fauzi \& Sastra Khusuma, 2020; Murtadlo, 2020). Pembelajaran tatap muka hanya diberikan maksimal 3 jam dalam seminggu, sehingga pembelajaran praktikum tidak dapat berjalan secara maksimal. Selain itu karakteristik siswa lebih suka belajar menggunakan bahan ajar berbasis multimedia dibandingkan membaca buku teks, selama pembelajaran daring yang dilaksanakakan secara umum bisa dilaksanakan, namun hanya beberapa yang mampu mengerti materi praktik animasi 2 dimensi, karena susah dilaksanakan tanpa panduan langsung, bahkan dengan video conference pun siswa cenderung jenuh belajar karena signal lemah yang mengakibatkan jalanya proses pembelajaran terputus-putus. Jika permasalahan tersebut dibiarkan akan memberikan dampak buruk terhadap hasil belajar siswa.

Oleh karena itu, dibutuhkan pembelajaran berbasis multimedia yang nantinya akan didistribusikan kepada siswa. Dengan media ini diharapkan mampu menjawab permasalahan pembelajaran praktikum yang terjadi di SMK Negeri 1 Kintamani. Diperlukan inovasi guna meningkatkan semangat siswa dalam proses belajar, salah satunya dengan mengembangkan pembelajaran berbasis multimedia. Pembelajaran berbasis multimedia berorientasi pada aplikasi yang fleksibel dan berkelanjutan yang mampu mengidentifikasi aspek permasalahan yang relevan sehingga diperlukan penerapannya untuk menyelesaikan permasalahan pembelajaran. PPKM di awal pandemi COVID-19 mengharuskan para guru di seluruh dunia melakukan digitalisasi praktik mengajar dari jarak jauh (Assunção Flores \& Gago, 2020; Ebner et al., 2020; König et al., 2020; Osman, 2020). Selain itu, guru dapat menggunakan skenario pembelajaran dengan memanfaatkan konten digital dengan mengunggah video, foto, atau materi kegiatan pembelajaran untuk dibagikan kepada siswa. Penerapan pembelajaran berbasis multimedia dirasa lebih efektif dibandingkan pembelajaran tradisional di masa pandemi COVID-19, karena pembelajaran dilakukan dengan menggunakan sistem online (Aisyah et al., 2020; Schwaighofer et al., 2016; Strelan et al., 2020). Guru harus termotivasi untuk mengembangkan teknologi, dan harus 
mampu mengintegrasikan teknologi dalam proses pembelajaran. Dengan demikian, motivasi berperan penting dalam pengembangan kompetensi dan kemampuan digital guru dalam mendistribusikan materi kepada siswa (Chiu \& Churchill, 2016; Jääskelä et al., 2017; Nalipay et al., 2019).

Beberapa temuan terkait pengembangan multimedia menyatakan pembelajaran multimedia dapat meningkatkan minat belajar siswa (Riyanto, 2017; Unaenah et al., 2020). Pembelajaran menggunakan multimedia dapat meningkatkan hasil belajar siswa (Abdurrahman et al., 2020; Susanto et al., 2013). Penelitian ini menggunakan model Integrated curriculum. Integrated adalah penyatuan menjadi satu kesatuan. Dalam kurikulum terpadu, pelajaran dipusatkan pada masalah atau topik tertentu, sehingga persepsi masing-masing guru mata pelajaran animasi 2D \& 3D bisa sama. Kombinasi yang digunakan menggunakan mode shift. Mode ini dilakukan untuk membagi jam latihan animasi menjadi 2 sesi, sehingga protokol kesehatan tetap bisa diterapkan. Tujuan dari penelitian ini adalah menciptakan produk ajar multimedia interaktif yang nantinya mampu meningkatkan respon belajar siswa, khususnya pada pembelajaran praktik animasi 2 dimensi, sehingga kegiatan pembelajaran berjalan dengan lancar sesuai dengan tujuan pembelajaran yang diinginkan.

\section{METODE}

Jenis penelitian yang akan dilakukan adalah jenis penelitian pengembangan atau R\&D (research and development). Penelitian dan pengembangan berorientasi pada pengembangan produk multimedia pembelajaran (Darmawan, 2015). Model pengembangan yang digunakan adalah model pengembangan Borg \& Gall. Langkah-langkah untuk mengembangkan model Borg and Gall pada Gambar 1. Tahap pengembangan Borg and Gall memiliki 10 tahapan yang harus dilalui, namun pada implementasi dalam penelitian ini hanya melaksanakan sampai tahap revisi produk. Berikut tahapan Borg and Gall yang dilakukan dalam penelitian. Pertama adalah mencari potensi dan masalah pembelajaran yang ada di tempat penelitian, kemudian mengumpulkan data yang diperoleh dari berbagai informasi yang peneliti gunakan sebagai data untuk melengkapi data penelitian yang berkaitan dengan masalah penelitian. Teknik analisis yang digunakan adalah teknik analisis statistik deskriptif. Kemudian membuat desain produk dari tahap pembuatan desain sistem hingga pembuatan aplikasi multimedia interaktif. Setelah itu, penyelesaian dilanjutkan dengan validasi desain. Validasi ini dilakukan untuk menilai sejauh mana produk multimedia interaktif yang dihasilkan dapat digunakan dalam proses pembelajaran. Selanjutnya, percobaan dilakukan oleh para ahli. Proses analisis data pada ujicoba ahli menggunakan kuesioner, yang kemudian dilanjutkan dengan proses revisi desain. Revisi desain dilakukan setelah ahli media, ahli desain dan ahli isi melakukan validasi terkait multimedia interaktif dengan memberikan penilaian dan saran untuk perbaikan aplikasi yang dikembangkan. Setelah selesai dilanjutkan dengan proses uji coba produk yang dilakukan langsung oleh siswa dengan melakukan uji coba perseorangan, uji coba kelompok kecil dan uji lapangan.. Subjek dalam penelitian ini adalah ahli media, ahli desain, ahli isi dan 30 siswa kelas XI Multimedia SMK Negeri 1 Kintamani. Metode pengumpulan data dilakukan dengan menggunakan kuesioner. Kisi-kisi instrumen angket uji yang dilakukan dalam pengembangan multimedia interaktif berbasis Integrated curriculum dalam pembelajaran animasi 2 dimensi pada Tabel 1, 2, dan 3.

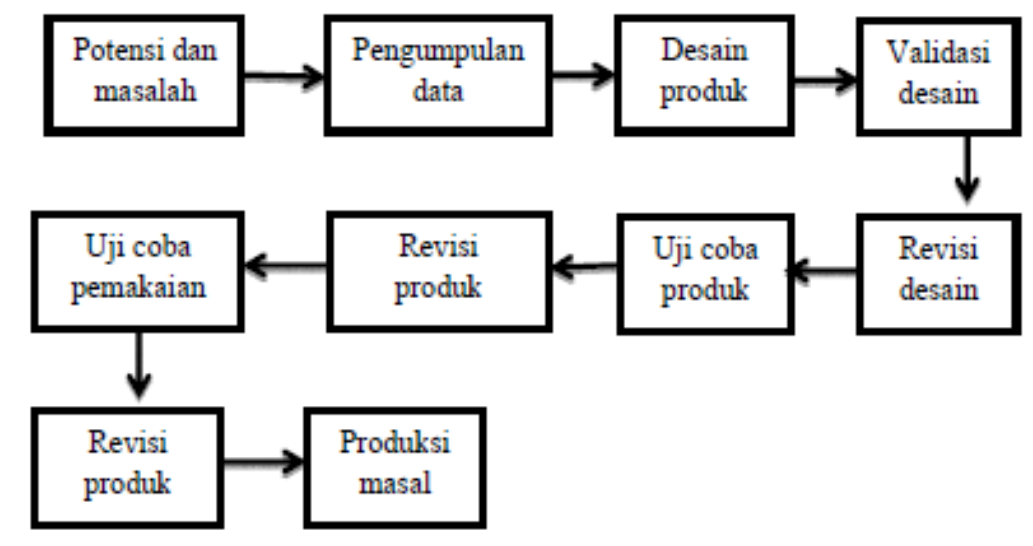

Gambar 1. Langkah-langkah Model Pengembangan Borg \& Gall (Sumber: Borg \& Gall, 1989) 
Tabel 1. Kisi- kisi Instrumen Penilaian Untuk Ahli Desain

\begin{tabular}{lllc}
\hline \multicolumn{1}{c}{ Aspek } & \multicolumn{1}{c}{ Indikator } & \multicolumn{1}{c}{ Butir Instrumen } & $\begin{array}{c}\text { Jumlah } \\
\text { Instrumen }\end{array}$ \\
\hline Aspek Desain MediaKelengkapan isi media & $1 \& 2$ & 2 \\
Pembelajaran & Desain tampilan & $3,4,5,6,7$ & 5 \\
& Kualitas Media & $8,9,10,11,12,13,14$ & 7 \\
& Kegunaan media & 15 & 1 \\
\multirow{2}{*}{ Manfaat } & Kebermanfaatan & $16 \& 17$ & 2 \\
& Membantu guru & $18 \& 19$ & 2 \\
\hline
\end{tabular}

Tabel 2. Kisi- kisi Instrumen Penilaian Untuk Ahli Materi

\begin{tabular}{llcc}
\hline \multicolumn{1}{c}{ Aspek } & \multicolumn{1}{c}{ Indikator } & Butir Instrumen & $\begin{array}{c}\text { Jumlah } \\
\text { Instrumen }\end{array}$ \\
\hline Desain Pembelajaran & Tujuan & $1,2,3$ & 3 \\
\cline { 2 - 4 } Materi & Fleksibelitas & 4 & 1 \\
& Isi materi & $5,6,7$ & 3 \\
Manfaat & Kelengkapan materi & $8,9,10,11,12$ & 5 \\
& Pengenalan lambang bilangan & 13 & 1 \\
& Kebermanfaatan bagi anak & $14,15,16,17,18$ & 5 \\
\hline & Kebermanfaatan bagi guru & $19 \& 20$ & 2 \\
\hline
\end{tabular}

Tabel 3. Kisi- kisi Instrumen Penilaian Untuk Ahli Desain

\begin{tabular}{llcc}
\hline \multicolumn{1}{c}{ Aspek } & \multicolumn{1}{c}{ Indikator } & $\begin{array}{c}\text { Butir } \\
\text { Instrumen }\end{array}$ & $\begin{array}{c}\text { Jumlah } \\
\text { Instrumen }\end{array}$ \\
\hline Pembelajaran & Ketepatan & 1 & 1 \\
& Petunjuk penggunaan & 2 & 1 \\
Pemrograman & Kesesuaian Program & 3 & 1 \\
& Penggunaan Tombol & $4,5,6$ & 3 \\
& Huruf, Animasi, Video, Audio, Gambar, & $7,8,9$, & 3 \\
& Tata letak, Warna Background, & $10,11,12,13,1$ & 4 \\
& Kemasan Produk & $4,15,16,17,18$, & 4 \\
& & 19,20 & 3 \\
\hline
\end{tabular}

Teknik analisis data menggunakan teknik analisis deskriptif dengan menggunakan wawancara dan kuesioner yang merupakan teknik pengumpulan data yang dilakukan dengan cara memberikan seperangkat pertanyaan atau pernyataan tertulis kepada responden untuk dijawab (Sugiyono, 2011). Lembar penilaian multimedia interaktif menggunakan skala Likert 1-5 dengan kriteria Sangat Kurang, Kurang, Cukup, Baik, dan Sangat Baik. Untuk mengukur tingkat pencapaian dan kualifikasi digunakan Tabel Konversi Tingkat Prestasi dengan Skala 5. Berikut ini adalah gambar tabel konversi tingkat prestasi dengan skala 5 dengan penilaian 1 = sangat tidak sesuai, $2=$ kurang sesuai , $3=$ cukup sesuai, $4=$ sesuai, 5 = sangat sesuai (Husnan, 2015). Konversi Tingkat Pencapaian dengan Skala 5 pada Tabel 4.

Tabel 4. Konversi Tingkat Pencapaian dengan Skala 5

\begin{tabular}{lll}
\hline Tingkat Pencapaian (\%) & Kualifikasi & Keterangan \\
\hline $90-100$ & Sangat Baik & Tidak perlu direvisi \\
$75-89$ & Baik & Tidak perlu direvisi \\
$65-74$ & Cukup & Direvisi \\
$55-64$ & Kurang & Direvisi \\
$0-54$ & Sangat Kurang & Direvisi \\
\hline
\end{tabular}

(Husnan, 2015). 


\section{HASIL DAN PEMBAHASAN}

Hasil

Pengembangan multimedia interaktif berbasis Integrated curriculum dengan shift mode merupakan langkah antisipasi pembelajaran di era new normal. Hasil yang diperoleh dalam penelitian ini merujuk pada Langkah-langkah pengembangan menurut borg \& Gall. Pertama, menentukan potensi dan masalah. Berdasarkan hasil wawancara yang diberikan oleh guru matapelajaran animasi 2 dimensi, menyebutkan bahwa pembelajaran praktik animasi 2 dimensi harus dilaksanakan karena dianggap sangat penting dalam kurikulum, pembelajaran masih menggunakan WA group dan google form yang hanya membagikan materi teori saja, namun di tengah pembelajaran online, masalah yang dihadapi siswa yaitu kurangnya signal di daerah pegunungan, hal ini menyebabkan kegiatan pembelajaran praktik menjadi terhambat. Sedangkan hasil wawancara ke 30 siswa yang menyebutkan siswa lebih tertarik belajar langsung menggunakan multimedia interaktif dengan alasan bisa dijalankan tanpa menggunakan quota internet. Analisis data dari jumlah siswa, hingga analisis kelayakan aplikasi yang dikembangkan. Analisis karakeristik siswa SMK Negeri 1 Kintamani dengan jumlah siswa 30 orang dengan presentase 46\% Lakilaki dan $54 \%$ perempuan, data 93\% siswa tinggal didaerah dengan akses internet yang lambat yaitu desa selulung, belantih,batukaang, mengani dan 7\% siswa tinggal dekat dengan akses internet/wifi yaitu dari desa tambakan yang tinggal dekat dengan bale banjar. Bagan persentase asal siswa disajikan pada Gambar 2 .

Tahap selanjutnya adalah pengumpulan data. Pada tahap ini peneliti mengumpulkan data yang diperoleh di SMK Negeri 1 Kintamani khususnya kelas XI Kompetensi Keahlian Multimedia dan semua yang berhubungan dengan pembelajaran praktek animasi 2 dimensi. Pada langkah ini peneliti mengecek keadaan laboratorium multimedia dengan melihat langsung spesifikasi komputer dan kelayakan software dan hardware serta menentukan materi pelajaran yang tertera pada mata pelajaran praktikum animasi 2 dimensi KI/KD. Materi yang disajikan dalam multimedia interaktif berdasarkan mata kuliah praktikum KI/KD Animasi 2 Dimensi yaitu pembuatan objek dalam aplikasi animasi 2 dimensi, jenis objek dan proses pembuatan objek, tweening animation, teknik pembuatan karakter 2 dimensi, membuat gerak digital puppeteer dalam animasi 2 dimensi, membuat background, dan menerapkan teknik produksi animasi serta membuat produk animasi 2 dimensi. Setelah semua data terkumpul, dilanjutkan dengan proses desain produk. Pada tahap perancangan multimedia interaktif, diperlukan storyboard dan bagan aktivitas. Proses pengembangan menggunakan software Adobe Flash, dengan keunggulan dapat menampilkan video disertai narasi serta gambar dan animasi yang memiliki kualitas yang baik. Tidak hanya tampilan tetapi juga dapat digunakan untuk membuat gambar, animasi, dan mengedit video dengan fitur yang memadai. Tampilan utama dari multimedia interaktif pada Gambar 3.

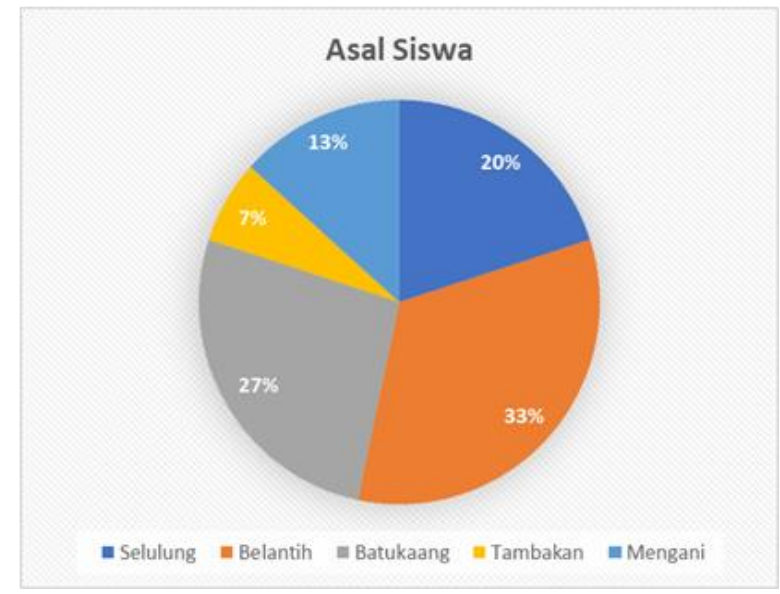

Gambar 2. Bagan persentase asal siswa

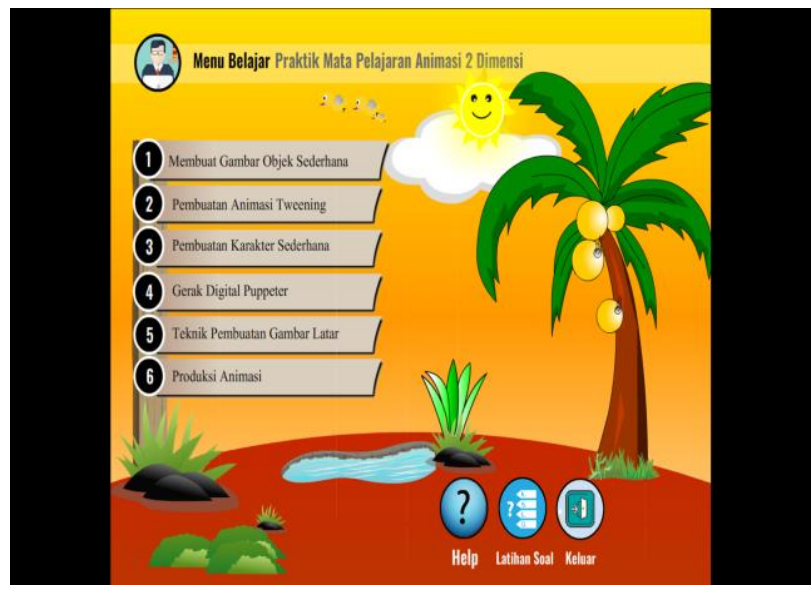

Gambar 3. Tampilan utama multimedia interaktif

Setelah multimedia interaktif dibuat, dilanjutkan dengan proses validasi desain. Validasi dilakukan oleh ahli media, ahli desain, dan ahli isi. Hasil pengujian ahli media dari aspek pewarnaan, penggunaan kata \& bahasa, grafik, animasi, video, suara, pengoperasian program, keamanan program, penanganan kesalahan dan kualitas fisik pengemasan diperoleh perhitungan yang baik sebesar 87\%. Hasil uji coba ahli desain dari aspek pembelajaran, kurikulum, isi, desain antarmuka, umpan balik dan penanganan masalah diperoleh perhitungan yang baik sebesar $89 \%$. Hasil uji ahli isi dari aspek materi yang disampaikan diperoleh perhitungan yang baik sebesar 88\%. Tahap selanjutnya adalah melakukan 
revisi desain dan pengembangan produk. Revisi desain dilakukan untuk menyempurnakan multimedia interaktif yang dikembangkan. Hasil revisi yang dilakukan pada saat uji coba ahli media pada Tabel 5.

Tabel 5. Hasil Revisi

\begin{tabular}{|c|c|c|}
\hline Uji Ahli & Revisi & h R \\
\hline Ahli Media & $\begin{array}{l}\text { 1. Animasi pada opening/intro tidak perlu panjang. } \\
\text { 2. Hapus file .fla setelah di publikasikan dalam } \\
\text { bentuk DVD } \\
\text { 3. Video harus terlihat jelas dengan kualitas video } \\
\text { yang lebih tinggi }\end{array}$ & $\begin{array}{l}\text { 1. Mengurangi animasi intro } \\
\text { menghapus file. Fla } \\
\text { 2. Meningkatkan kualitas video } \\
\text { tutorial. }\end{array}$ \\
\hline sain & $\begin{array}{l}\text { 1. Kontras warna diperhatikan agar teks terlihat } \\
\text { jelas. } \\
\text { 2. Berikan pernyataan pada akhir soal ketika lulus } \\
\text { KKM dan tidak lulus KKM. } \\
\text { 3. Perhatikan redaksi pada soal pilihan ganda. }\end{array}$ & $\begin{array}{l}\text { erjelas kontras warna. } \\
\text { nbah pernyataan pada } \\
\text { oal. } \\
\text { ah redaksi pada soal } \\
\text { ganda. }\end{array}$ \\
\hline Ahli Isi & $\begin{array}{l}\text { 1. Sesuaikan isi yang disajikan dengan KI/KD. } \\
\text { 2. Video pada sub menu materi ditambah unt } \\
\text { meningkatkan pemahaman khususnya pada ma } \\
\text { pelajaran praktik animasi } 2 \text { dimensi. }\end{array}$ & $\begin{array}{l}\text { 1. Menyesuaikan materi dengan } \\
\text { KI/KD. } \\
\text { 2. Menambah materi pada } \\
\text { video. }\end{array}$ \\
\hline
\end{tabular}

Tahap selanjutnya adalah pengujian produk dengan melibatkan 30 siswa SMK Negeri 1 Kintamani pada program keahlian multimedia. Uji coba dilakukan melalui uji coba perseorangan, uji coba kelompok kecil dan uji coba lapangan/kelompok besar dengan tetap mengikuti protokol kesehatan selama pandemi COVID-19. Pada proses uji perseorangan yang dilakukan oleh 3 siswa SMK Negeri 1 Kintamani diperoleh hasil perhitungan yang sangat baik yaitu $90 \%$. Ketiga responden tersebut memberikan pernyataan positif pada seluruh pernyataan dalam angket yang diberikan, sehingga ujicoba perseorangan dikatakan valid dan layak untuk dilanjutkan ke proses uji coba selanjutnya. Kemudian uji coba kelompok kecil yang dilakukan dengan melibatkan 8 responden SMK Negeri 1 Kintamani diperoleh persentase sebesar 91\%. Jika dikonversikan ke tabel konversi tingkat pencapaian dengan skala 5, maka dalam kualifikasi sangat baik. Uji coba kelompok besar/lapangan dilakukan dengan mode shift. Uji coba ini dilakukan dengan 3 shift dengan jumlah responden sebanyak 30 siswa SMK Negeri 1 Kintamani pada program keahlian multimedia. Berdasarkan hasil perhitungan diperoleh hasil sebesar $89 \%$ berada pada kategori baik. Selanjutnya merevisi produk dari masukan siswa dalam proses uji coba. Beberapa revisi dilakukan yaitu menambah volume video, menambah jumlah video dan memperjelas ikon tombol. Grafik ujicoba keseluruhan pengembangan multimedia interaktif berbasis Integrated curriculum dengan shift mode dalam pembelajaran praktikum Animasi 2D disajikan pada Gambar 4. Hasil pengujian menunjukkan bahwa multimedia interaktif layak digunakan di SMK Negeri 1 Kintamani.

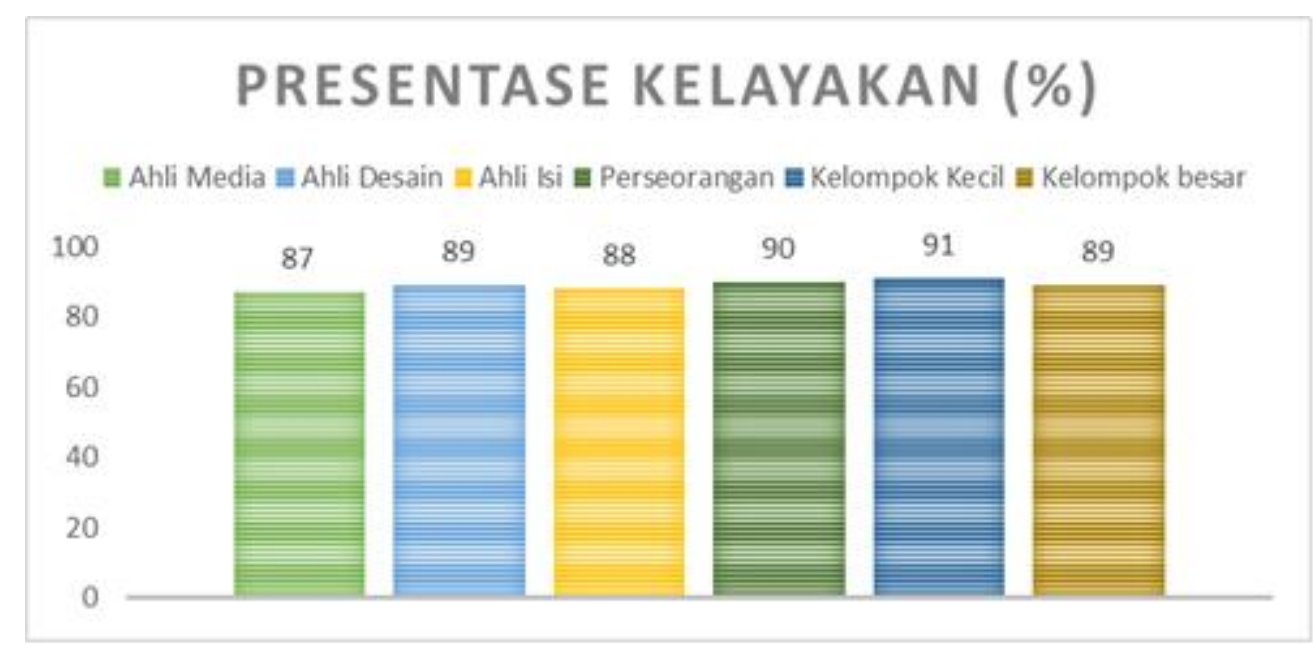

Gambar 4. Grafik ujicoba terhadap pengembangan multimedia interaktif Berbasis Integrated curriculum Dengan Shift Mode Pada Pembelajaran Praktik Animasi 2 Dimensi 


\section{Pembahasan}

Multimedia interaktif merupakan salah satu sarana untuk meningkatkan kegiatan proses belajar mengajar dengan tujuan menjadikan pembelajaran lebih menarik dengan mengintegrasikan teks, suara, dan video serta mampu meningkatkan pengetahuan dan pemahaman siswa dalam pembelajaran. Pembelajaran multimedia telah menghasilkan sejumlah teori dan temuan empiris. Banyak tren dan isu yang muncul, menunjukkan sifat pembelajaran multimedia yang kompleks dan dinamis. Untuk dapat menghasilkan produk tertentu dilakukan penelitian yaitu analisis kebutuhan dan menguji keefektifan produk tersebut agar dapat berfungsi di masyarakat luas. (Abbas et al., 2020; Jing et al., 2020; Sugiyono, 2014). Multimedia interaktif berbasis Integrated curriculum dengan Shift Mode dalam pembelajaran praktik animasi 2 dimensi efektif dan layak digunakan di SMK Negeri 1 Kintamani. Multimedia interaktif merupakan solusi untuk meningkatkan kegiatan pembelajaran dan mampu memberikan visualisasi materi secara nyata, video dan animasi di dalamnya memungkinkan pembelajaran mandiri dan terdapat perbedaan hasil belajar yang signifikan pada penggunaan multimedia interaktif dibandingkan pembelajaran menggunakan buku teks (Agustina, 2017; Armansyah et al., 2019; Brom et al., 2018; Farida \& Rahayu, 2017). Penambahan elemen gambar, animasi dan grafik mampu memberikan visualisasi materi secara nyata yang berdampak langsung pada siswa dan video di dalamnya mendukung proses belajar mandiri (Eitel, 2016; Ögren et al., 2017).

Pengembangan multimedia interaktif dengan bantuan video tutorial sangat efektif dilaksanakan, yang diharapkan mampu memberikan solusi dalam proses pembelajaran di masa pandemi COVID-19 karena multimedia interaktif mampu mengajak siswa untuk berpartisipasi membangun atau menumbuhkan semangat belajar siswa.guna meningkatkan pemahaman konsep (Bustanil S et al., 2019; Prismanata \& Ismaniati, 2017; Pujawan, 2019; Santhalia \& Sampebatu, 2020). Penambahan elemen multimedia pada materi pembelajaran memberikan efek meningkatkan emosi belajar siswa, meningkatkan rasa percaya diri, meningkatkan kinerja siswa, mendukung pemahaman dan pengambilan keputusan, sehingga berdampak pada hasil belajar siswa. (Lindner et al., 2017, 2021; Rasch \& Schnotz, 2009; Stark et al., 2018). Selain membangkitkan respon, motivasi dan minat siswa, multimedia interaktif juga dapat membantu siswa meningkatkan pemahaman dan sikap belajar untuk mempelajari pengetahuan faktual dan menambah waktu belajar, menyajikan data secara menarik, memudahkan interpretasi data dan memadatkan informasi. Multimedia interaktif meningkatkan pemahaman dan meningkatkan semangat dalam proses pembelajaran. Secara umum manfaat yang dapat diperoleh dari penggunaan multimedia dalam pembelajaran di sekolah adalah proses pembelajaran lebih menarik, lebih interaktif, jumlah waktu mengajar dapat dikurangi, kualitas belajar siswa dapat ditingkatkan dan proses belajar mengajar dapat dilakukan. proses bisa dilakukan dimana saja dan kapan saja (Dwi agus setiawan \& Nur Kumala, 2020; Knoop-van Campen et al., 2020; Manurung, 2021; Tomita, 2018).

Penggunaan google classroom sebagai kombinasi multimedia interaktif berdampak positif terhadap peningkatan hasil belajar, minat dan motivasi siswa dalam belajar serta menumbuhkan sikap kreatif pada siswa atau siswa (Hikmatiar et al., 2020; Maharani \& Kartini, 2019). Dalam pengembangannya menggunakan model Integrated curriculum. Dengan pembelajaran terpadu ini, siswa diharapkan memiliki kemampuan untuk mengidentifikasi, mengumpulkan, menilai, dan menggunakan informasi yang ada di sekitarnya secara bermakna sehingga menghasilkan kemampuan pengetahuan yang terintegrasi. (Erwin Akib et al., 2020; Haenilah, 2017). Dalam penyajian menggunakan bantuan video tutorial, pembelajaran berbasis video mampu mempercepat pemahaman siswa terhadap materi pelajaran dengan sistem pembelajaran mandiri dalam kondisi pandemi COVID-19, orang tua memiliki peran yang sangat vital bagi keberhasilan belajar siswa karena menjadi pengganti guru ketika belajar di sekolah. rumah (Achmad et al., 2021; Mardliyah et al., 2020).

Temuan ini diperkuat dengan temuan sebelumnya menyatakan melalui pembelajaran multimedia dapat meningkatkan minat belajar siswa (Riyanto, 2017; Unaenah et al., 2020). Pembelajaran menggunakan multimedia dapat meningkatkan hasil belajar siswa (Abdurrahman et al., 2020; Susanto et al., 2013). Pembelajaran melalui multimedia terintegrasi kurikulum, siswa sangat antusias mempelajari materi animasi 2 dimensi, siswa menjadi lebih mudah memahami materi latihan animasi 2 dimensi, mampu mengatasi masalah lambatnya akses internet di pedesaan, dan peran orang tua sangat penting dalam mengawasi kegiatan praktiknya di rumah selama masa pandemi covid-19. Batasan penelitian yang dilakukan dalam metode Borg \& Gall yaitu sampai tahap revisi produk, revisi ini dilakukan setelah melakukan tahap ujicoba kelompok besar dalam mencari respon siswa. Implikasi penelitian yang telah dilakukan dengan memanfaatkan multimedia interaktif berbasis Integrated curriculum adalah terjadi peningkatan respon belajar siswa sehingga berdampak langsung terhadap semangat belajar siswa dan keaktifan serta partisipasi siswa dalam pembelajaran, karena dapat digunakan sebagai media pembelajaran mandiri. Untuk penelitian selanjutnya, disarankan untuk mengembangkan multimedia interaktif dengan model kearifan lokal dengan implementasi video yang lebih menarik sebagai bahan ajar 
siswa. Produk yang dikembangkan tidak dapat digeneralisasikan secara umum karena hanya sebatas pembelajaran praktek animasi 2 dimensi.

\section{SIMPULAN}

Kondisi pandemi Covid-19 seperti sekarang ini pembelajaran tetap dilakukan di rumah masingmasing dengan metode daring (dalam jaringan) atau metode luring (jaringan luar). Salah satu inovasi yang dikembangkan yaitu Multimedia Interaktif berbasis Integrated curriculum dengan Shift Mode sebagai langkah antisipasi pembelajaran di era new normal. Pengembangan Multimedia Interaktif sangat efektif diterapkan dalam proses pembelajaran dimasa pandemic covid-19 karena mampu menjadi solusi dalam meningkatkan respon siswa dalam proses pembelajaran praktik animasi 2 dimensi di SMK Negeri 1 Kintamani.

\section{DAFTAR PUSTAKA}

Abbas, B., Halimah, A., Nursalam, N., \& Mattoliang, L. A. (2020). Pengembangan Media Pembelajaran Berbasis Multimedia. Al Asma: Journal of Islamic Education, 2(1), 97. https://doi.org/10.24252/asma.v2i1.13380.

Abdurrahman, Jampel, I. N., \& Sudatha, I. G. W. (2020). Pengembangan Multimedia Pembelajaran Interaktif untuk Meningkatkan Hasil Belajar IPS. Journal of Education Technology, 4(1), 52. https://doi.org/10.23887/jet.v4i1.24091.

Achmad, Z. A., Fanani, M. I. D., Wali, G. Z., \& Nadhifah, R. (2021). Video Animasi Sebagai Media Pembelajaran Efektif bagi Siswa Sekolah Dasar di Masa Pandemi COVID-19. JCommsci - Journal of Media and Communication Science, 4(2), 54. https: //doi.org/10.29303/jcommsci.v4i2.121.

Agustina, A. (2017). Pembelajaran Konsep Ikatan Kimia Dengan Animasi Terintegrasi Lcd Projector Layar Sentuh (Low Cost Multi Touch White Board). JTK (Jurnal Tadris Kimiya), 1(1), 8-13. https: //doi.org/10.15575/jta.v1i1.1163.

Aisyah, E. N., Iriyanto, T., Hardika, H., Rosyidamayani, \& Maningtyas, T. (2020). The Cyber Ethics of Academic Communication Based on Early Childhood Education Student Perception in Universitas Negeri Malang. Proceedings of the International Conference on Learning Innovation 2019 (ICLI 2019). https://doi.org/10.2991/assehr.k.200711.001.

Apriyanti, C. (2020). Distance Learning and Obstacles During Covid-19 Outbreak. Jurnal Ilmiah Pendidikan Dasar, 7(2), 68. https://doi.org/10.30659/pendas.7.2.68-83.

Armansyah, F., Sulton, S., \& Sulthoni, S. (2019). Multimedia Interaktif Sebagai Media Visualisasi Dasardasar Animasi. Jurnal Kajian Teknologi Pendidikan, 2(3), 224-229. https://doi.org/10.17977/um038v2i32019p224.

Asri Devi, N. M. I. (2020). Pengembangan Media Pembelajaran Puzzle Angka untuk Meningkatkan Kemampuan Mengenal Lambang Bilangan. Jurnal Ilmiah Pendidikan Profesi Guru, 3(3), 416. https://doi.org/10.23887/jippg.v3i3.28331.

Assunção Flores, M., \& Gago, M. (2020). Teacher education in times of COVID-19 pandemic in Portugal: national, institutional and pedagogical responses. Journal of Education for Teaching, 46(4), 507516. https://doi.org/10.1080/02607476.2020.1799709.

Borup, J., Graham, C. R., West, R. E., Archambault, L., \& Spring, K. J. (2020). Academic Communities of Engagement: an expansive lens for examining support structures in blended and online learning. Educational Technology Research and Development, 68(2), 807-832. https: //doi.org/10.1007/s11423-020-09744-x.

Brom, C., Stárková, T., \& D’Mello, S. K. (2018). How effective is emotional design? A meta-analysis on facial anthropomorphisms and pleasant colors during multimedia learning. Educational Research Review, 25, 100-119. https://doi.org/10.1016/j.edurev.2018.09.004.

Bustanil S, M., Asrowi, \& Adianto, D. T. (2019). Pengembangan Media Pembelajaran Interaktif Berbasis Video Tutorial Di Sekolah Menengah Kejuruan. JTP - Jurnal Teknologi Pendidikan, 21(2), 119-134. https://doi.org/10.21009/jtp.v21i2.11568.

Chiu, T. K. F., \& Churchill, D. (2016). Adoption of mobile devices in teaching: changes in teacher beliefs, attitudes and anxiety. Interactive Learning Environments, 24(2), 317-327. https: //doi.org/10.1080/10494820.2015.1113709.

Darmawan, D. (2015). Teknologi Pendidikan. PT. Remaja Rosdakarya.

Diputra, K. S. (2016). Pengembangan Multimedia Pembelajaran Tematik Integratif Untuk Siswa Kelas Iv Sekolah Dasar. JPI (Jurnal Pendidikan Indonesia), 5(2), 125. https://doi.org/10.23887/jpi- 
undiksha.v5i2.8475

Dwi agus setiawan, \& Nur Kumala, F. (2020). Multimedia Interaktif Tipe Adobe Flash CS6 Berbasis Kurikulum 2013 Dalam Meningkatkan Literasi Verbal Siswa Sekolah Dasar. Jurnal Pendidikan Dasar Nusantara, 6(1), 32-49. https://doi.org/10.29407/jpdn.v6i1.14358.

Ebner, M., Schön, S., Braun, C., Ebner, M., Grigoriadis, Y., Haas, M., Leitner, P., \& Taraghi, B. (2020). COVID19 epidemic as E-learning boost? Chronological development and effects at an Austrian university against the background of the concept of "E-learning readiness." Future Internet, 12(6). https://doi.org/10.3390/FI12060094.

Eitel, A. (2016). How repeated studying and testing affects multimedia learning: Evidence for adaptation to task demands. Learning and Instruction, 41, 70-84. https://doi.org/10.1016/j.learninstruc.2015.10.003.

Erwin Akib, Muhammad Erwinto Imran, Saiyidah Mahtari, Muhammad Rifqi Mahmud, Anggy Giri Prawiyogy, Irfan Supriatna, \& MT. Hartono Ikhsan. (2020). Study on Implementation of Integrated Curriculum in Indonesia. IJORER : International Journal of Recent Educational Research, 1(1), 3957. https://doi.org/10.46245/ijorer.v1i1.24.

Farida, N., \& Rahayu, S. (2017). Multimedia Interaktif Pecahan Untuk Pembelajaran Matematika Pada Siswa Kelas IV SDN Gadang 1 Malang. Math Didactic: Jurnal Pendidikan Matematika, 3(2), 132139. https://doi.org/10.33654/math.v3i2.65.

Fauzi, I., \& Sastra Khusuma, I. H. (2020). Teachers' Elementary School in Online Learning of COVID-19 Pandemic Conditions. Jurnal Iqra': Kajian Ilmu Pendidikan, 5(1), 58-70. https://doi.org/10.25217/ji.v5i1.914.

Firdausi, A. R., \& Barnawi. (2012). Profil Guru SMK Profesional. Ar-Ruzz Media.

Graham, C. R., Borup, J., Short, C. R., \& Archambault, L. (2019). K-12 blended teaching: A guide to personalized learning and online integration. EdTech Books. http://edtechbooks.org/k12blended.

Haenilah, E. Y. (2017). Efektifitas desain pembelajaran terpadu Berbasis Core Content di Sekolah Dasar. Sekolah Dasar: Kajian Teori Dan Praktik Pendidikan, 26(1), 39-48. https://doi.org/10.17977/um009v26i12017p039.

Hanik, E. U. (2020). Self directed learning berbasis literasi digital pada masa pandemi covid-19 di Madrasah Ibtidaiyah. ELEMENTARY: Islamic Teacher Journal, 8(1), 183. https://doi.org/10.21043/elementary.v8i1.7417.

Hikmatiar, H., Sulisworo, D., \& Wahyuni, M. E. (2020). Pemanfaatan Learning Manegement System Berbasis Google Classroom Dalam Pembelajaran. Jurnal Pendidikan Fisika, 8(1). https://doi.org/10.26618/jpf.v8i1.3019.

HM, M. A. (2018). Inovasi Sistem Pendidikan. Inspiratif Pendidikan, $7(2), \quad 161$. https://doi.org/10.24252/ip.v7i2.7851.

Husnan, S. (2015). Dasar-Dasar Teori Portofolio dan Analisis Sekuritas. (Edisi 5). UPPN STIM YKPN.

Jääskelä, P., Häkkinen, P., \& Rasku-Puttonen, H. (2017). Teacher Beliefs Regarding Learning, Pedagogy, and the Use of Technology in Higher Education. Journal of Research on Technology in Education, 49(34), 198-211. https://doi.org/10.1080/15391523.2017.1343691.

Jing, J. L. J., Yi, T. P., Bose, R. J. C., McCarthy, J. R., Tharmalingam, N., \& Madheswaran, T. (2020). Hand sanitizers: A review on formulation aspects, adverse effects, and regulations. International Journal of Environmental Research and Public Health, 17(9). https://doi.org/10.3390/ijerph17093326.

Knoop-van Campen, C. A. N., Segers, E., \& Verhoeven, L. (2020). Effects of audio support on multimedia learning processes and outcomes in students with dyslexia. Computers and Education, 150(February), 103858. https://doi.org/10.1016/j.compedu.2020.103858.

König, J., Jäger-Biela, D. J., \& Glutsch, N. (2020). Adapting to online teaching during COVID-19 school closure: teacher education and teacher competence effects among early career teachers in Germany. European Journal of Teacher Education, 43(4), 608-622. https: //doi.org/10.1080/02619768.2020.1809650.

Kuswanto, J., \& Walusfa, Y. (2017). Pengembangan Multimedia Pembelajaran pada Mata Pelajaran Teknologi Informasi dan Komunikasi Kelas VIII. Innovative Journal of Curriculum and Educational Technology IJCET, 6(2), 58-64. https://doi.org/10.15294/ijcet.v6i2.19335.

Lindner, M. A., Eitel, A., Barenthien, J., \& Köller, O. (2021). An integrative study on learning and testing with multimedia: Effects on students' performance and metacognition. Learning and Instruction, 71. https://doi.org/10.1016/j.learninstruc.2018.01.002.

Lindner, M. A., Eitel, A., Strobel, B., \& Köller, O. (2017). Identifying processes underlying the multimedia effect in testing: An eye-movement analysis. Learning and Instruction, 47, 91-102. https://doi.org/10.1016/j.learninstruc.2016.10.007.

Maharani, N., \& Kartini, K. S. (2019). Penggunaan google classroom sebagai pengembangan kelas virtual 
dalam keterampilan pemecahan masalah topik kinematika pada mahasiswa jurusan sistem komputer. PENDIPA Journal of Science Education, 3(3), 167-173. https://doi.org/10.33369/pendipa.3.3.167-173.

Manurung, P. (2021). Multimedia Interaktif Sebagai Media Pembelajaran Pada Masa Pandemi Covid 19. AlFikru: Jurnal Ilmiah, 14(1), 1-12. https://doi.org/10.51672/alfikru.v14i1.33.

Mardliyah, S., Yulianingsih, W., \& Putri, L. S. R. (2020). Sekolah Keluarga: Menciptakan Lingkungan Sosial untuk Membangun Empati dan Kreativitas Anak Usia Dini. Jurnal Obsesi : Jurnal Pendidikan Anak Usia Dini, 5(1), 576. https://doi.org/10.31004/obsesi.v5i1.665.

Murtadlo. (2020). Pembelajaran Daring Pada msa Pandemi Covid 19 di Lingkungan Pesantren. Akademia Pustaka.

Nalipay, M. J. N., Mordeno, I. G., Semilla, J. roel B., \& Frondozo, C. E. (2019). Implicit Beliefs about Teaching Ability, Teacher Emotions, and Teaching Satisfaction. Asia-Pacific Education Researcher, 28(4), 313-325. https://doi.org/10.1007/s40299-019-00467-z.

Ögren, M., Nyström, M., \& Jarodzka, H. (2017). There's more to the multimedia effect than meets the eye: is seeing pictures believing? Instructional Science, 45(2), 263-287. https://doi.org/10.1007/s11251-016-9397-6.

Osman, M. E. T. (2020). Global impact of COVID-19 on education systems: the emergency remote teaching at Sultan Qaboos University. Journal of Education for Teaching, 46(4), 463-471. https: //doi.org/10.1080/02607476.2020.1802583.

Persada, Y. I., Djatmika, E. T., \& Degeng, I. N. S. (2020). Pelaksanaan Pendekatan Scientific Dalam Pembelajaran Tematik. Jurnal Pendidikan: Teori, Penelitian, Dan Pengembangan, 5(1), 114-120. https://doi.org/10.17977/jptpp.v5i1.13151.

Prismanata, Y., \& Ismaniati, C. (2017). Pengembangan multimedia pembelajaran geografi berbasis memory sport pada materi litosfer untuk peserta didik SMA. Jurnal Inovasi Teknologi Pendidikan, 4(1), 97. https://doi.org/10.21831/jitp.v4i1.11621.

Pujawan, K. A. H. (2019). Pengembangan Multimedia Interaktif Berbasis Video Tutorial Pada Mata Kuliah Multimedia I (Desain Grafis) di politeknik Ganesha Guru. Journal of Education Technology, 2(1), 61. https://doi.org/10.23887/jet.v2i1.13810.

Quezada, R. L., Talbot, C., \& Quezada-Parker, K. B. (2020). From Bricks and Mortar to Remote Teaching: A Teacher Education Program's Response to COVID-19. Journal of Education for Teaching, 46(4), 472-483. https://doi.org/10.1080/02607476.2020.1801330.

Rasch, T., \& Schnotz, W. (2009). Interactive and non-interactive pictures in multimedia learning environments: Effects on learning outcomes and learning efficiency. Learning and Instruction, 19(5), 411-422. https://doi.org/10.1016/j.learninstruc.2009.02.008.

Riyanto, W. D. (2017). The Effectiveness of Interactive Multimedia in Mathematic Learning. (Utilizing Power Points for Students with Learning Disability). 1(1), 55-63. https://doi.org/10.20961/ijpte.v1i1.8400.

Santhalia, P. W., \& Sampebatu, E. C. (2020). Pengembangan multimedia interaktif dalam membantu pembelajaran fisika di era Covid-19. Jurnal Inovasi Pendidikan IPA, 6(2). https://doi.org/10.21831/jipi.v6i2.31985.

Schwaighofer, M., Bühner, M., \& Fischer, F. (2016). Executive functions as moderators of the worked example effect: When shifting is more important than working memory capacity. Journal of Educational Psychology, 108(7), 982-1000. https://doi.org/10.1037/edu0000115.

Sepulveda-Escobar, P., \& Morrison, A. (2020). Online teaching placement during the COVID-19 pandemic in Chile: challenges and opportunities. European Journal of Teacher Education, 43(4), 587-607. https: //doi.org/10.1080/02619768.2020.1820981.

Stark, L., Malkmus, E., Stark, R., Brünken, R., \& Park, B. (2018). Learning-related emotions in multimedia learning: An application of control-value theory. Learning and Instruction, 58, 42-52. https://doi.org/10.1016/j.learninstruc.2018.05.003.

Strelan, P., Osborn, A., \& Palmer, E. (2020). The flipped classroom: A meta-analysis of effects on student performance across disciplines and education levels. Educational Research Review, 30. https://doi.org/10.1016/j.edurev.2020.100314.

Sugiyono. (2014). Metode Penelitian Kualitatif dan R\&D. Alfabeta.

Sujana, I. W. C. (2019). Fungsi Dan Tujuan Pendidikan Indonesia. Adi Widya: Jurnal Pendidikan Dasar, 4(1), 29. https://doi.org/10.25078/aw.v4i1.927.

Surjono, H. D. (2017). Multimedia Pembelajaran Interaktif Konsep dan Pengembangan. UNY Press.

Susanto, Dewi, N. R., \& Irsadi, A. (2013). Pengembangan Multimedia Interaktif dengan Education Game pada Pembelajaran IPA Terpadu Tema Cahaya untuk Siswa SMP/MTs. USEJ - Unnes Science 
Education Journal, 2(1). https://doi.org/10.15294/usej.v2i1.1829.

Tomita, K. (2018). Does the Visual Appeal of Instructional Media Affect Learners' Motivation Toward Learning? TechTrends, 62(1), 103-112. https://doi.org/10.1007/s11528-017-0213-1.

Unaenah, E., Setyadi, arif rahman, Sari, putri widiya, El-Abida, S. F., Agustina, N., Fauziah, S., \& Leonardho, R. (2020). Pengembangan Aplikasi Pembelajaran Matematika Tentang Pengukuran Waktu, Panjang Dan Berat Untuk Sekolah Dasar. Jurnal Edukasi Dan Sains, 2(1), 192-201. 